\title{
GOETHE, SCHLEIERMACHER Y LA VALORACIÓN DEL ION
}

\section{GOETHE, SCHLEIERMACHER AND THE APPRAISAL OF THE ION ${ }^{1}$}

\author{
JAVIER AGUIRRE* \\ Universidad del País V asco (San Sebastián)
}

RESUMEN: Los despectivos comentarios de Goethe y Schleiermacher sobre el Ion provocaron las dudas de los platonistas alemanes del siglo XIX acerca de la autoría platónica del diálogo. Asimismo, salvo contadas excepciones, durante ese siglo y parte del siglo XX la valoración del mismo fue escasa. El articulo intenta mostrar que, en lo relativo a su autoria, no hay serias razones para pensar que no se trate de una obra genuina de Platón; y en lo relativo a su valor filosófico, que el Ion representa un paso fundamental en el proyecto platónico de suplantar el papel de la poesía en el monopolio educativo de la polis.

Palabras Clave: Ion, autenticidad, poesía, Goethe, Schleiermacher.

ABSTRACT: The derogatory remarks of Goethe and Schleiermacher about the Ion caused the nineteenth-century German Platonists to doubt Plato's authorship of the dialogue. Also, with few exceptions, during this century and part of twentieth century, the Ion was very poorly valued. The article attempts to show that, with regard to its authorship, there are no serious reasons to believe that this is not a genuine work of Plato; and, in terms of its philosophical value, that the Ion is a critical step in the Platonic project to supplant the role of poetry in the educational system of the polis. Key words: Ion, authenticity, poetry, Goethe, Schleiermacher.

KEYwORDs: Ion, authenticity, poetry, Goethe, Schleiermacher.

\footnotetext{
${ }^{1}$ Deseo mostrar mi más profundo agradecimiento a los profesores John Bremer (Cambridge College) y Graham Parkes (University College Cork) por toda la ayuda prestada durante mi estancia de investigación en la UCC (Cork) durante el primer cuatrimestre del curso 2011-2012, a cuyo periodo pertenece este artículo como parte del trabajo realizado.

* Dirección postal del autor: Departamento de Filosofía, Facultad de Filosofía (UPV/EHU), Avda. De Tolosa, 70, 20018 San Sebastián. E-mail: javier.aguirre@ehu.es
} 


\section{Goethe y Schleiermacher ante el Ion platónico}

El diálogo Ion nos ha llegado junto a los diálogos Hipias Mayor, Hipias Menor y Menéxeno, formando parte de la séptima de las nueve tetralogías en que han sido transmitidos los diálogos platónicos. Aunque el texto moderno de la mayor parte de los diálogos depende casi en su totalidad de dos manuscritos, el Codex Bodleianus, MS. E. D. Clarke 39 (en la Bodleian Library de Oxford) y el Codex Parisinus 1807 (en la Biblioteque Nationale de París), por circunstancias de la transmisión la séptima tetralogía desapareció del Codex Bodleianus, al que pertenecía. Afortunadamente, se han conservado otros manuscritos, de los que depende el texto moderno del Ion, siendo el principal el Codex Venetus T (en la biblioteca de San Marcos de Venecia), probablemente del siglo X, al que hay que añadir dos manuscritos encontrados en Viena, el Codex Vindobonensis W y el Codex Vindobonensis F. La ordenación de los diálogos en tetralogías se ha atribuido a Trasilo, autor romano de comienzos de la Era Cristiana. Diógenes Laercio (III, $56)^{2}$ afirma que la decisión de reunir los diálogos en grupos de cuatro procede del deseo del propio Platón de seguir el ejemplo de las tragedias. La idea tiene su apoyo en el hecho de que los diálogos Teeteto, Sofista y Político aparecen vinculados a un cuarto, el Filósofo, y los diálogos República, Timeo y Critias, al Hermócrates, diálogos cuya escritura es anunciada por el propio Platón, aunque finalmente no fueran escritos ${ }^{3}$. En cualquier caso, parece claro que la organización de los diálogos en tetralogías es una práctica anterior a Aristófanes de Bizancio (c. 257-180 a. C.), de quien Diógenes Laercio (III, 61) afirma que se propuso renovar los criterios de ordenación, pasando de tetralogías a trilogías. Según la descripción realizada por Diógenes Laercio (III, 49), el sistema de clasificación de Trasilo responde al método de la diaeresis o división, mediante el cual los diálogos son progresivamente divididos en dos subgrupos hasta conformar un número de ocho tipos distintos (físico, lógico, ético, político, mayéutico, tentativo, demostrativo y refutatorio). Los diálogos platónicos fueron probablemente ordenados en tetralogías por este método incluso antes del final del s. IV a. C, si bien, a pesar de la creencia de Trasilo, el ordenamiento no habría sido obra de Platón, sino de los responsables de la Academia tras la muerte del maestro. Se sabe que Platón era

\footnotetext{
2 Sigo la traducción de Bredlow (2010).

${ }^{3}$ Cf. Político 257a y Critias 108a-c. Sobre esta y otras cuestiones referentes a la transmisión de la obra de Platón puede consultarse el excelente trabajo de Philip (1970).

${ }^{4}$ Philip, J. A. (1970): «The Platonic Corpus», Phoenix, Vol. 24, no 70, p. 305.
} 
muy meticuloso con sus manuscritos, por lo que bien pudo haber vuelto sobre ellos una y otra vez a fin de revisarlos. En este sentido, PHILIP ${ }^{4}$ ha señalado que «los manuscritos que él dejaba eran manuscritos con adiciones, supresiones, lecturas alternativas y variantes terminológicas», de modo que su fijación y clasificación debió ser labor de los posteriores responsables de la Academia. Siguiendo también la costumbre de Platón (D.L. III, 57-58), cada diálogo posee dos títulos, correspondientes al nombre del interlocutor principal y al tema tratado. En el caso de nuestro diálogo, los títulos son Ion o Sobre la Ilíada (Íon è perì Iliádos), que Diógenes (III, 60) describe como «tentativo» (peirastikós) $)^{5}$. En lo que respecta a la debatida cuestión de la autenticidad de los diálogos, es importante señalar que ninguno de los considerados espúreos en la antigüedad aparece en las tetralogías recogidas por Diógenes (cf. D.L. III, 62). Sin embargo, a pesar de la información transmitida por este autor, y a pesar de que desde la Antigüedad hasta el siglo XVIII se asume sin la menor duda la autoría platónica del Ion, el siglo XIX constituye un periodo de permanente debate en torno a su autenticidad. De hecho, una buena parte de los principales platonistas alemanes, incluidos Ast, Zeller, Ritter y el propio Wilamowitz, negaron la autoría platónica del diálogo, por considerarlo un texto impropio del filósofo ateniense. A la hora de explicar la génesis de este rechazo y del dilatado debate posterior, hay dos hechos que deben ser señalados: en primer lugar, la negativa valoración que el gran poeta Goethe hizo del diálogo con motivo de su inclusión en el corpus platónico por parte del traductor Stolberg. En segundo lugar, la pobre valoración que Schleiermacher hizo del diálogo y las hipótesis que sobre su autoría planteó en su introducción al Ion. Hay que señalar que, paradójicamente, ni Goethe ni Schleiermacher negaron la autoría platónica del diálogo, y que el rechazo de muchos platonistas posteriores a aceptarlo como obra de Platón se debe, más bien, a la despectiva valoración que del mismo realizaron los dos carismáticos intelectuales ${ }^{6}$.

\footnotetext{
${ }^{5}$ Sobre los títulos de los diálogos platónicos, son valiosas las pertinentes aclaraciones de Rijksbaron (2007: 15-23).

${ }^{6}$ Una excelente revisión de las distintas opiniones sobre la autenticidad del diálogo se encuentra en Flashar, H. (1958): Der Dialog Ion als Zeugnis platonischer Philosophie, Berlin: Akademie Varlag, pp. 1-16. Una útil exposición del debate sobre la autenticidad del diálogo y de otros problemas vinculados a esta cuestión —la elección de un rapsoda como interlocutor, las reminiscencias con otros diálogos y otros autores o el lugar del Ion en el corpus platónico- se encuentra en OTT, S. D. (1992): A commentary on Plato's Ion, Dissertation for the degree of PhD., Ann Arbor (MI): UMI, pp. 37-56. Una revisión telegráfica de la variedad de posturas sobre todas esas cuestiones se encuentra en CAMPBELL, P. N. (1986): «The Ion: Argument and Drama», Res Publica litterarum 9, 59-68, part. 59-60.
} 
El breve y crítico texto de Goethe (1749-1832), escrito en $1797^{7}$, está dirigido contra el traductor de la obra de Platón, F. L. G. Stolberg (1750-1819), quien había incluido la traducción del diálogo Ion entre los textos del filósofo. El poeta alemán ya había mostrado su rechazo a la inclusión del texto en dos cartas dirigidas a sus amigos F. Schiller y W. von Humboldt ${ }^{8}$, lo que indica el sincero malestar que la inclusión del Ion le había causado. En este breve y combativo texto, Goethe se pregunta «cómo puede el Ion (...) ser presentado como un libro canónico, siendo que este pequeño diálogo no es sino una burla (Persiflage)». El poeta mismo responde a la cuestión, afirmando que «sin duda ello se debe a que el final del diálogo evoca la inspiración divina». Y continúa: «Desgraciadamente, aquí, como en otras frecuentes ocasiones, Platón no hace sino ironizar» (104). A juicio de Goethe, el Sócrates platónico descrito en el Ion es una simple máscara, «una figura imaginaria en la cual Sócrates no se reconoce más que en la de Aristófanes» (105). Y en cuanto a la figura del rapsoda, señala que «un tal hombre (...) no puede haber obtenido su talento más que por la tradición o el ejercicio. Probablemente estaba dotado de un porte aventajado, de una buena voz, y de un corazón capaz de emoción; pero con todo ello, no se trata más que de un naturalista, un simple hombre de recetas que jamás había reflexionado sobre su arte ni sobre las obras, sino que giraba mecánicamente en un círculo cerrado, considerándose a pesar de ello poeta y estimado probablemente por toda Grecia» (106). Goethe compara al Sócrates descrito en el Ion con el poeta cómico Aristófanes, niega que Platón haya tenido ningún interés por instruir al lector, y niega también que el tema del diálogo tenga nada que ver con la poesía. Goethe se queja, asimismo, de las falacias en las que cae Sócrates, como cuando en 538 b le pregunta al rapsoda si es el poeta o el auriga quien mejor comprende cuando Homero habla de la conducción del carro, cuestión a la que, a juicio de Goethe, el rapsoda podría haber respondido: «seguramente el poeta, pues el auriga sabe solamente si Homero habla correctamente, pero el rapsoda inteligente ve si Homero habla conveniente-

7 Goethe (1797): Plato als Mittgenosse einer Christlichen Offenbahrung, en GrumaCH, E. (1949): Goethe und die Antike, Berlín: De Gruyter, II, 758-762. Existe traducción francesa: Platon, contemporain de la révélation chrétienne, en PRADEAU, J.-F. (2001): Platon. Ion, suivi de Édouard Mehl: Deux lectures de l'Ion: M. Ficin et J. W. Goethe et Jean-Luc Nancy: Le partage des voix. Paris: Ellipses, pp. 103110. Las referencias pertenecen a la traducción francesa.

${ }^{8}$ Las cartas están fechadas el 21 de noviembre y el 3 de diciembre de 1795; las referencias en las cartas al trabajo de Stolberg están recogidas en Grumach, E. (1949): Goethe und die Antike, Berlín: De Gruyter, II, p. 758.

ÉNDOXA: Series Filosóficas, n. 29, 2011, pp. 73-92. UNED, Madrid 
mente, si es que él cumple con su deber de poeta, y no como cronista de cursos de carro» (107). Porque, a juicio del poeta, «sólo la intuición y el sentimiento, y no propiamente el conocimiento, revelan la jurisdicción del poeta épico, con su mirada libre sobre el mundo y todo lo que le concierne». Y siendo así, «¿quién tiene necesidad de refugiarse en la inspiración divina?» (107). Pero lo que más sorprende a Goethe del diálogo platónico es la dureza con la que es tratado el rapsoda, y que Ion, «una vez reconocida su incompetencia en diferentes artes (...) finalice (541b) nada menos que pretendiendo sentirse particularmente competente en el dominio de la estrategia» (109). Y también considera «una maldad puramente aristofanesca» dejarle escoger a Ion entre ser un hombre injusto o ser un hombre divino. Por todo ello, concluye Goethe, «quien nos exponga ahora lo que hombres como Platón han dicho seriamente, por placer o medio placer, por convicción íntima o de modo dialéctico, rendirá un servicio extraordinario y contribuirá en gran medida a nuestra instrucción» (109), en clara alusión crítica a Stolberg por haberse tomado en serio el diálogo. En resumen, Goethe encuentra en el Ion una simple burla, un humor exagerado, aristofanesco, vacío de contenido filosófico, ajeno al tratamiento serio de la poesía y de la inspiración poética, de contenido falaz y sofístico. Y por ello, rechaza incluirlo entre los diálogos canónicos. Tal como ya hemos apuntado, el mayor interés del breve texto de Goethe reside en el hecho de que sus críticas han servido de punto de partida de numerosos platonistas del XIX para negar la autenticidad del diálogo, cosa que Goethe, por otro lado, no pretendió. Pero si el breve texto de Goethe tuvo su influencia en la posterior valoración del diálogo, su trascendencia en los estudios platónicos es minúscula si la comparamos con lo que supuso la obra del teólogo y filósofo alemán Schleiermacher.

La monumental obra de Schleiermacher (1768-1834) supuso, ella sola, la superación de la interpretación neoplatónica de la filosofía platónica, cuya influencia se había dejado sentir durante más de mil quinientos años. Iniciada durante el Platonismo medio, en torno al siglo II de nuestra era, con el Didascálico de Albino, la interpretación neoplatónica del pensamiento de Platón culminaría en la obra de Plotino y Proclo, pero habría de extenderse hasta el mismo Renacimiento, con la importante traducción latina de los diálogos por parte de Marsilio Ficino. Ficino no sólo tradujo la obra de Platón, sino también la de Plotino, difundiendo la opinión de que el filósofo neoplatónico era el intérprete por excelencia de Platón. Este modo de entender la obra platónica sería dominante hasta 
comienzos del s. XIX ${ }^{9}$. El propio comentario de Ficino al diálogo Ion ${ }^{10}$, datado en 1482, constituye un ejemplo que ilustra a la perfección aquello en lo que se había convertido la obra de Platón para sus intérpretes neoplatónicos, y que Schleiermacher pretendía superar Al contrario que Goethe, el escritor florentino entiende que el tratamiento de la locura divina (enthousiasmós o furor divinus) en el Ion está hecho con seriedad, sin tinte alguno de ironía. A su juicio, el tema del diálogo lo constituye la descripción de la caída y la posterior ascensión del alma, con la ayuda de la iluminación de su parte racional, y el paso de la misma por los diferentes grados que separan los cuerpos del Uno. Según Ficino, «la locura divina es una iluminación racional del alma, mediante la que dios vuelve a elevar el alma, descendida a regiones inferiores, a encumbradas sedes» (31). Al contrario que Goethe, para quien la inspiración poética en el Ion no es sino una simple metáfora, Ficino realiza una seria y detallada descripción del fenómeno. Merece la pena reproducir el fragmento con el que Ficino describe el proceso de la inspiración, con la que pone punto final a la introducción al diálogo: «Al decir Dios, Platón se refiere a Apolo, y con las Musas, a las almas de de las esferas del mundo. Júpiter es ciertamente la mente de Dios, de ella se sucede Apolo, mente del alma del mundo, y alma del mundo entero, y de él, las almas de las ocho esferas celestes que son llamadas las nueve Musas puesto que mientras mueven los cielos de manera armoniosa, producen música, melodía que se distribuye en nueve sonidos, siendo ocho sonidos los tonos de las esferas y las nueve Sirenas cantando al Dios producen un único canto. Así, Apolo se deduce de Júpiter y las Musas se siguen de Apolo, o lo que es lo mismo, el séquito de las Musas es llevado por la mente del alma del mundo porque así como aquella mente (sc. Apolo) es iluminada por Júpiter, ella también ilumina las almas de las esferas del mundo. Éstos son los estadios por los que desciende la locura poética: Júpiter toma a Apolo. Apolo ilumina a las Musas. Las Musas despiertan y estimulan las almas delicadas e insuperables de los poetas. Los poetas inspirados inspiran a su vez a los intérpretes. Finalmente los intérpretes conmueven al auditorio» (43-45). Obvia

\footnotetext{
${ }^{9}$ Un breve y erudito resumen de la historia de los paradigmas hermenéuticos de Platón, en ReAle, G. (2003): Por una nueva interpretación de Platón. Relectura de la Metafísica de los grandes diálogos a la luz. de las doctrinas no escritas, Barcelona: Herder [1993], pp. 31-74.

${ }^{10}$ In Platonis Ionem vel de furore Poetico, ad Laurentium Medicem virum magnanimum. Utilizo el texto latino con traducción al castelleno que se encuentra en FICINO, M. (1993): Sobre el furor divino y otros textos, selección de textos, introducción y notas de Pedro Azara, traducción de Juan Maluquer y Jaime Sainz, Barcelona: Anthropos, pp. 30-47. El texto original con traducción francesa se encuentra en el ya citado PRADEAU (2001: 82-99).
} 
decir que nada de ello cabe inferir de los contenidos del Ion, ni siquiera del Fedro, con el que Ficino vincula nuestro diálogo. Schleiermacher dará un giro revolucionario al modo de entender la obra de Platón.

\section{EI debate sobre la autenticidad del Ion}

El nuevo paradigma que habría de sustituir al neoplatónico es formulado por Schleiermacher, quien entre los años 1804 y 1828 lleva a cabo una fiel traducción de la obra de Platón, en seis volúmenes, con una Introducción general e introducciones a cada uno de los diálogos donde expone los criterios de interpretación de la obra del filósofo ${ }^{11}$. Los criterios propuestos por Schleiermacher se adaptaban al contexto cultural del primer romanticismo y de la filosofía idealista, movimientos que habrían de desarrollarse en torno al año 1800, pero fundamentalmente al pensamiento de Friedrich Schlegel y Friedrich Schelling, autores cuya influencia iba a hacerse notar. Los principios en los que se basa la nueva lectura de la obra de Platón son fundamentalmente tres: en primer lugar, Schleiermacher asume que los escritos platónicos que nos han llegado en forma de diálogo constituyen la expresión por excelencia de la comunicación filosófica de Platón, y deben ser entendidos como una síntesis inseparable de forma y contenido $(14)^{12}$. Este modo de entender el diálogo platónico tiene su origen en la concepción romántica de la unidad del arte y de la filosofía proclamado por Schlegel, y también por Schelling, quien, sobre la base de la filosofía de la identidad, habría de establecer la unidad de la filosofía y la poesía. La preferencia de Schleiermacher por el Platón de los diálogos frente al Platón de la tradición indi-

${ }^{11}$ Schleiermacher, D. (2010): Platons Werke, Charleston: Nabu Press [1804-1828]. Existen varias ediciones de la obra completa, accesibles en www.archive.org. También existe traducción inglesa, accesible en internet, de la Introducción general y de las introducciones a cada uno de los diálogos en Dobson, W. (ed.) (1836): Schleiermacher. Introductions to the Dialogues of Plato. Cambridge-London. Sobre los principios generales de la interpretación de Schleiermacher y las premisas teóricas que los sustentan han escrito importantes trabajos DILTHEY, W. (1970): Leben Schleiermachers, Berlin [1898], vol. I, pp. 37-52, GADAMER, H.-J. (1969): «Schleiermacher platonicien», Archives de Philosophie, 28-39, KRÄMER, H. J. (1989): Platone e i fundamenti della metafisica. Saggio sulla teoria dei principi e sulle dottrine non scritte di Platone, Milano: Vita e Pensiero, pp. 51-75 y REALE, G. (2003): Por una nueva interpretación de Platón. Relectura de la Metafísica de los grandes diálogos a la luz de las doctrinas no escritas, Barcelona: Herder [1993], pp. 54-69.

${ }^{12}$ Utilizo la paginación de Dobson, W. (ed.) (1836): Schleiermacher. Introductions to the Dialogues of Plato. Cambridge-London., pp. 1-47. 
recta se funda en gran medida en el carácter artístico ejemplar de la obra escrita de Platón y su gran eficacia comunicativa. En segundo lugar, Schleiermacher estima que los diálogos platónicos, tomados en su totalidad, poseen una unidad doctrinal y expresan un sistema preciso, expuesto según un plan general y organizado según un criterio didáctico. Este plan general se divide en etapas que se suceden unas a otras, partiendo de un nivel elemental, para alcanzar un nivel constructivo y sistemático explícito (18-ss., 40-ss.). La obra de Platón es concebida, por consiguiente, como un organismo en desarrollo, idea que no era ajena a la filosofía de la identidad expuesta por Schelling. De este esquema general quedaba excluido el sistema de principios transmitido por la tradición indirecta, que establecía la presencia de dos principios, el Uno y de la Díada, como culminación de la estructura ontológica de la realidad. En tercer lugar, según la interpretación de Schleiermacher, los diálogos poseen un carácter autárquico, tanto individual como colectivamente, y el pensamiento de Platón se halla exclusivamente en ellos. Por consiguiente, la tradición indirecta pierde su valor, incluida la que se remonta a los discípulos directos de Platón (1, 9-ss., 23-ss.). La autarquía de los diálogos platónicos establecida por Schleiermacher se adapta al principio de la autarquía del texto bíblico, establecido por los reformistas protestantes, según el cual la Biblia sólo debe ser interpretada a partir de sí misma (sola scriptura) y sólo puede ser comprendida a partir de sí misma (sui ipsus interpres), lo que implicaba la interpretación literal del texto escrito y el rechazo de las interpretaciones alegórica, moral y anagógica, propias de la hermenéutica medieval. A este respecto, hay que recordar que Schleiermacher fue un reconocido teólogo protestante, de modo que se limitó a aplicar el principio de la exégesis bíblica a los escritos de Platón.

El establecimiento de estos criterios hermenéuticos va a determinar el orden atribuido a los diálogos, el lugar por ellos ocupado en el despliegue del sistema platónico, y también la valoración de los mismos. Así, el Fedro es considerado por Schleiermacher el primer diálogo desde el punto de vista lógico y cronológico, porque su tema lo constituye la Dialéctica, entendida como impulso y método de la filosofía, y porque en sus páginas se encuentra la semilla de la filosofía platónica entera. El Parménides y el Protágoras, en tanto que exposición de la parte teórica y la parte práctica de la filosofía - la exposición de las aporías del conocimiento de las Ideas y la enseñanza de la virtud, respectivamente- son considerados obras de la primera época, mientras que la República y el Timeo son vistos como la coronación de la construcción artístico-filosófica de Platón, la solución de los 
enigmas precedentes, y el punto final de la obra que se había propuesto escribir. A juicio de Schleiermacher, este orden de los diálogos es evidente. La posición del Ion en la ordenación de los diálogos establecida por Schleiermacher está íntimamente vinculada a la posición del Fedro, tal como se indica en la breve introducción al $I_{0}{ }^{13}$. La valoración que Schleiermacher hace del diálogo es muy pobre, y de hecho sólo asume la autoría parcial de Platón. Schleiermacher inicia su breve Introducción al Ion señalando que el objetivo del diálogo es probarle al rapsoda Ateniense (sic), en primer lugar, que si su labor de interpretación y crítica es una ciencia o un arte, no puede reducirse a un poeta, sino a todos ellos, pues los temas tratados por todos ellos son los mismos, y el arte de la poesía es uno e indivisible; y en segundo lugar, que no corresponde al rapsoda el juzgar al poeta, sino al especialista en cada uno de los temas tratados en los pasajes narrados por el poeta. Tras ello, Schleiermacher añade que «será evidente para todo lector que no puede haber sido el objetivo último de Platón el avergonzar a un rapsoda de tal manera» (145), habida cuenta que los rapsodas ocupaban uno de los lugares más bajos del estrato social, por lo que hay que suponer que el rapsoda sólo debe ser visto como «la concha», y que la poesía es realmente el verdadero tema del diálogo. A juicio de Schleiermacher, las alusiones al Fedro sustentan tal opinión. Además, como en el Fedro, la inspiración poética en oposición a la técnica es uno de los temas desarrollados en el Ion, por lo que el autor se pregunta «cómo habría sido escrito expresamente un diálogo con el propósito de contener una mera repetición de lo que ya ha sido dicho con unos pocos claros ejemplos» (146). El objeto real del Ion es la naturaleza del arte de la poesía, pero el diálogo carece de una verdadera instrucción sobre la cuestión, así como una deficiente ejecución, a lo que hay que añadir que el Fedro, que Schleiermacher fecha antes que el Ion, ya se había pronunciado adecuadamente sobre la cuestión (cf. 147-149). Como consecuencia de todo ello, al abordar la cuestión de la autoría del diálogo, Schleiermacher propone dos hipótesis: «O uno de los alumnos de Platón pudo haber compuesto el diálogo a partir de un boceto apresurado de su maestro, en el que algunos pasajes particulares fueron elaborados con más detalle que otros, o al menos tomando indicaciones y expresiones de Platón como guías (...), o el diálogo, en efecto, proviene de Platón, pero sólo como una composición deficientemente ejecutada, que apenas habría sido corregido por una mano final. El único período en el que puede afirmarse que ha sido compuesto es lo más pronto posible

${ }^{13}$ Las referencias pertenecen a las introducciones al Fedro y al Ion de la traducción de DOBSON $(48-73,145-150)$. 
tras la escritura del Fedro» (149). Como palabras finales de la Introducción, Schleiermacher concluye: «En cualquier caso, este breve diálogo, revelando tantas características sospechosas, y desprovisto de cualquier tendencia filosófica, difícilmente podría reclamar un lugar distinto que el que le asignamos» (150). Incluso en una nota final a una edición posterior, Schleiermacher añadirá: «Pero Bekker señala con más decisión éste y los siguientes diálogos como no genuinos y, al hacerlo, tiene mi pleno consentimiento» (151). La negativa opinión de Schleiermacher, unida a la de Goethe, marcará en gran medida el destino del Ion durante todo el siglo XIX. En efecto, la influencia Schleiermacher se vio primeramente reflejada en los trabajos de Bekker ${ }^{14} \mathrm{y} \mathrm{Ast}^{15}$, quienes asumieron con respecto al Ion las sospechas del teólogo protestante, e incluso dieron un paso más al negar la autenticidad del diálogo, paso que, tal como hemos señalado, sería aceptado posteriormente por el propio Schleiermacher. También negaron la autoría platónica del Ion Zeller ${ }^{16}$ y Ritter ${ }^{17}$. Zeller parte de la premisa de Schleiermacher de que el Ion es posterior al Fedro y de que con respecto a éste no representa ningún avance, con la única diferencia de que lo dicho en el Fedro a propósito del poeta es referido en el Ion al rapsoda. Como Schleiermacher, también ve sospechoso que Platón haya elegido a un rapsoda como interlocutor de Sócrates para tratar el tema de la inspiración (261-2). Pero además, añade una nueva objeción, al argumentar que todo lo afirmado por Platón sobre el tema de la inspiración de un modo disperso en numerosos diálogos, se encuentra reunido en el Ion. En efecto, Zeller encuentra en el Ion la referencia a la inspiración de las Musas de Fedro 245a, la identificación de la experiencia del poeta con la del profeta y el adivino de Apología 22c, el contraste entre la técnica y la inspiración divina de Menón 99c, la transmisión de la inspiración de Banquete 215e, y el supuesto conocimiento universal del poeta de Repúbica 598c-d. Basándose en este hecho, Zeller plantea que un autor posterior pudo haber reunido en un diálogo propio lo afirmado por Platón de forma dispersa (262-3). El argumento de Zeller será retomado muy posteriormente por Diller ${ }^{18}$. Por su parte, Ritter basa su rechazo de la autenticidad del Ion

${ }^{14}$ Bekker, I. (1816): Platonis Dialogui, Graece et Latine, Berolini: Imprisis GE. Reimini, I, 2, p. 267.

${ }^{15}$ Ast, F. (1818): Platons Leben und Schriften, Leipzig, pp. 468ss.

${ }^{16}$ Zeller, E. (1875): Die Philosophie der Griechen, Leipzig, II, 1, p. 248.

${ }^{17}$ RiTTER, C. (1888): Untersuchungen über Plato, Stuttgard, pp. $15 \mathrm{ss}$.

${ }^{18}$ Diller, H. (1955): «Probleme des Platonischen Ion», Hermes, 83, p. 187. Diller encuentra incongruencias en el texto, un método dialéctico singular, la ausencia de temas importantes como el de la mímesis, y una escasa unidad en el diálogo. En consecuencia, el platonista alemán plantea volver a la tesis de Schleiermacher de que el diálogo es sólo parcialmente platónico. 
en razones de tipo estilístico ${ }^{19}$. En la nómina de notables platonistas alemanes del siglo XIX que niegan en algún momento la autoría platónica del Ion, se encuentra el propio Wilamowitz ${ }^{20}$, quien, muy influido por Goethe, comienza rechazando la autoría platónica del diálogo para, finalmente, tras tres décadas de dudas al respecto, aceptarla. De esta lista, que Tigerstedt ${ }^{21}$ ha calificado de «imponente», destaca sin embargo la ausencia de K. F. Hermann ${ }^{22}$, quien desde el primer momento acepta sin fisuras la autoría platónica del Ion. En este sentido, es digno de elogio el juicio independiente y certero del platonista alemán, quien, enfrentándose a la corriente dominante de la época, no sólo aborda correctamente el análisis del contenido y el contexto de la obra, sino que refuta gran parte de los argumentos esgrimidos contra su autenticidad. A juicio de Hermann, la mayor parte de las dudas planteadas por Schleiermacher no proceden del análisis de los diálogos en sí mismos, sino del punto de vista preconcebido de la metódica conexión de los escritos platónicos (432). Por consiguiente, lo que a su juicio debe ser puesto en duda es la cronología de Schleiermacher, por ser de donde derivan las objeciones con respecto a la autenticidad del Ion (434-5). Con respecto al hecho esgrimido por Schleiermacher de que este diálogo no aporta nada a lo ya afirmado en el Fedro, Hermann explica que el punto de vista desde el que es tratada la inconsciencia de la creación poética en el Ion es distinto al del Fedro: el Ion, que a su juicio pertenece al periodo socrático, debe vincularse al punto de vista de la Apología, donde los poetas son colocados entre aquellos que presumen de conocer más de lo que realmente saben por el hecho de poseer conocimiento en un

${ }^{19}$ Ritter atribuye al Ion un uso poco común de las partículas interrogativas tí mén (531d8) y pộs (541a1), así como de las fórmulas de respuesta égoge, émoige y dokê̂ moi, objeciones que se unen al uso transitivo de hormo (534c) o el uso de legousi (534c), ya planteadas por Schleiermacher. Estas débiles objeciones han sido rechazadas por JANELL, W. (1901): Quaestiones Platonicae, Neue Jahrbicher fiir Philologie, Supp. 26, pp. 265ss. Breves y certeros comentarios a las objeciones contra la autoría platónica del Ion se encuentra en Meridier, E. (1978): Platon. Oeuvres Complètes, Paris: Les belles lettres [1931], pp. 19-22 y Verdenius, W. J. (1943): «L' Ion de Platon», Mnemosyne III, 11, pp. 233-8.

${ }^{20}$ El erudito alemán rechaza la autenticidad del Ion en WilamowiTZ-MOLLENDORF, U. v. (1893): Aristoteles und Athen, Berlin: Weidmann, p. 188 n. 4, pero la acepta en WiLAmOwITZ-MoLLENDORF, U. v. (1920): Platon, Berlin, II, pp. 32-36, si bien lo considera «el ensayo de un principiante», p. 36.

21 Tigerstedt, E. N. (1969): «Plato’s Idea of Poetical Inspiration», Commentationes Humanarum Litterarum, 44, Helsinki: Societas Scientiarum Fennica, p. 16.

22 Hermann, K. F. (1976): Geschichte und systém der Platonischen Philosophie, New York: Arno [1839], pp. 435-39 
ámbito concreto, y no al punto de vista del Fedro, centrado en el tema de la creación literaria. En este sentido, frente a la concepción sistemática del platonismo defendida por Schleiermacher, la opinión de Hermann es la de que los diálogos reflejan más bien el crecimiento intelectual del filósofo a lo largo del tiempo, y la de que el Ion pertenece al primer estadio o periodo socrático (436). En cuanto a la extrañeza por la elección de un rapsoda como interlocutor de Sócrates, Hermann señala certeramente que el rapsoda representa a la poesía épica en un momento en el que ya no existen los poetas épicos. Además, el propósito de Platón consiste en mostrar la diferencia entre el verdadero conocimiento y la intuición, para lo que sirve tanto el rapsoda como el poeta (437). Incluso si, tal como observa Schleiermacher, el rapsoda es considerado una figura de baja escala social, ello sirve mejor al propósito de Platón, puesto que éste puede mostrar que el poeta no debe ser considerado superior, pues su mérito sólo depende de la fortuita inspiración y no del conocimiento $(436-8)^{23}$. Finalmente, al contrario de lo que posteriormente será afirmado por Zeller, el grado de acuerdo entre el Ion y otros diálogos, lejos de ser una objeción, constituye un argumento a favor de su autoría platónica (438-9). Desde la distancia, sorprende que los certeros argumentos de Hermann no tuvieran una aceptación general, lo cual es atribuible al enorme prestigio de Schleiermacher y de Zeller, que condicionó la lectura de nuestro breve diálogo ${ }^{24}$. En todo caso, una vez que queda en evidencia la debilidad de las

\footnotetext{
${ }^{23}$ Hermann es consciente de que, en una gran medida, las objeciones a la autoría platónica del Ion proceden de la presencia de un rapsoda como interlocutor de Sócrates. Goethe y Schleiermacher se vieron influidos sin lugar a dudas por los despectivos comentarios lanzados por Jenofonte en el Banquete III, 6 y en Recuerdos de Sócrates IV, 2, 10, donde los rapsodas son presentados como personajes omnipresentes y estúpidos, de donde erróneamente dedujeron un bajo lugar en su escala social. Sin embargo, por los comentarios del propio Platón en las Leyes 659d y en el Ion 535d-e y passim, debemos suponer que gozaban de una enorme popularidad entre la población, independientemente de que las clases más formadas intelectualmente los miraran con cierto desprecio. Más que la razón esgrimida por Hermann para explicar la elección de un rapsoda como interlocutor, me inclino a pensar que la razón de fondo estriba, precisamente, en su enorme presencia social, en su alto reconocimiento popular y en su condición de vínculo necesario en la transmisión de los valores de la tradición.

${ }^{24}$ Hay que señalar, no obstante, que otros especialistas alemanes del siglo XIX, antes y después de Hermann, asumen sin conflicto la autoría platónica del Ion; cf., por ejemplo, NiTZSCH, G. G. (1822): Platonis dialogus Ion (Prolegomena), Lipsiae, STAllbaum, G. (1857): Prolegomena ad Ionem, Gothae, p. 341, DümmLer, F. (1882): Antisthenica, Halle, pp. 27ss., STÄHLIN, F. (1901): Die Stellung der Poesie in der platonischen Philosophie, Munich, pp. 30ss., MEYER, E. (1899): Forschungen zur alten Geschichte, II, pp. 174ss.
} 
objeciones procedentes de la lengua y el estilo del diálogo, la inconsistencia de las objeciones procedentes del carácter y comportamiento de los personajes, el carácter más que dudoso de la cronología establecida por Schleiermacher y el hecho evidente de que el contenido del Ion es manifiestamente platónico, parece que poco cabe añadir al respecto de su autoría. Y de hecho, con algunas notables excepciones $^{25}$, la gran mayoría de los especialistas del siglo XX han aceptado sin mayor problema la autoría platónica del Ion. Hay que añadir, sin embargo, que la pobre valoración que de él tuvieron Goethe y Schleiermacher ha resistido mucho más el paso del tiempo. Un breve repaso a alguno de los principales trabajos del siglo XX da una muestra de ello.

\section{Valoración literaria y filosófica del Ion}

La pobre valoración del Ion no sólo cabe atribuirla a Goethe, Schleiermacher o Wilamowitz. Por el contrario, otros especialistas posteriores han compartido esa opinión, y no sólo en el ámbito alemán. Por no alargar innecesariamente la lista, podemos tomar como ejemplo la opinión expresada por Taylor y Guthrie, dos de los grandes helenistas británicos del siglo XX. En su influyente trabajo de 1926, Taylor ${ }^{26}$ incluye el Ion entre los «Diálogos socráticos menores» (23), y de él afirma que «poco hay que decir acerca de este leve diálogo sobre la naturaleza de la inspiración poética. Las principales ideas sugeridas son expuestas mucho más a fondo en esos importantes diálogos que tendremos ocasión de tratar más adelante» (38). Por su parte, Guthrie ${ }^{27}$ le dedica al diálogo unas pocas páginas en su monumental historia de la filosofía griega. En su comentario, repleto, por otro lado, de muy certeras y agudas observaciones, afirma que «la atención que se le ha dedicado a este opúsculo, cuya extensión no sobrepasa unas

\footnotetext{
${ }^{25}$ A la ya mencionada obra de Diller hay que añadir la obra de MOREAU, J. (1939): «Les thèmes platoniciens de l' Ion de Platon», Revue des études grecques, 52, pp. 419-428, quien atribuye la factura del diálogo a un discípulo de Platón en su intento de producir un texto análogo el Fedro (428). Moreau esgrime el viejo argumento de que el diálogo no aporta nada nuevo a lo ya dicho en otros diálogos (421-3), el carácter sospechoso de su exposición didáctica (423-5) y el final no aporético del diálogo (425). En todo caso, Moreau reconoce que «el contenido del diálogo es integralmente platónico» (419).

${ }^{26}$ TAYLOR, A. E. (1926): Plato: the Man and his Work, London, pp. 38-41.

${ }^{27}$ Guthrie, W. K. C. (1990): Historia de la Filosofía Griega. IV: Platón. Platón. El hombre y sus diálogos: primera época, Madrid: Gredos [1062], pp. 195-207.
} 
cuantas páginas y que no es serio más que a medias, se explica, naturalmente, por la importancia que se le atribuye a cualquier elemento que arroje luz sobre la actitud de Platón en relación con los poetas y la poesía» (200-1). Guthrie añade que «no merece mucho la pena indicar las falacias cometidas por S. en esta obrita (...)» (198 n. 247), quien «aborda un poema como si fuera un manual de instrucciones» y donde «nunca se mencionan los criterios estéticos» (201). Y finaliza afirmando: «Podemos dejar aquí esta pequeña y alegre pieza, cuya relación con la poesía nos ha conducido probablemente a concederle una atención más seria que la que es conveniente para la diversión que Platón tenía la intención de proporcionarnos con ella» (206). Se trata de la opinión de dos destacadísimas personalidades pertenecientes a distintas generaciones de platonistas británicos cuya influencia, incluso hoy en día, no cabe desdeñar. Pero, ¿es el Ion realmente un diálogo leve, sin contenido filosófico, escrito medio en broma o, lo que es peor, al modo aristofanesco?, ¿ ‘se trata de una obra menor escrita por diversión o resentimiento, o simplemente esbozada en vista a un posterior desarrollo? De nuevo hay que llamar la atención sobre el hecho de que no todos los platonistas han compartido esta opinión, mayoritaria durante décadas. Sin salir del ámbito británico, tenemos las opiniones de Grote ${ }^{28}$, Jowett ${ }^{29}$, o Lamb ${ }^{30}$, tres destacadísimas figuras pertenecientes a distintas generaciones de platonistas que no sólo asumen la autenticidad del Ion sin rastro de duda sino que valoran el diálogo muy positivamente. Así, Grote escribe: «Opino que [el Ion] es auténtico, y quizás relativamente temprano, pero no veo ninguna razón para la crítica despectiva que a menudo se le ha dirigido» (454). Y Jowett: «El Ion es el más breve o casi el más breve de todos los escritos que llevan el nombre de Platón, y su autenticidad no está certificada por ningún testimonio externo; la gracia y belleza de esta obrita es la única prueba y tal vez una prueba suficiente de su autenticidad» (277). Y Lamb: «Esta graciosa pieza es notable, no sólo por las pruebas que ofrece de la popularidad y del procedimiento de los recitales de Homero durante los siglos V y IV, o por su brillante testimonio de la habilidad de Platón en la caracterización de personajes, sino también por su insistencia —más implícita que expresada- de la doctrina de que ningún arte, a pesar de ser calurosamente aceptado y alentado por la multitud, puede tener un valor real a menos que se base en

${ }^{28}$ Grote, G. (1867): Plato and the Other Companions of Socrates, London, pp. 454-67.

${ }^{29}$ JOwetT, B. (1914): The dialogues of Plato, vol. IV, New York, [1871].

${ }^{30}$ LAmB, W. R. M. (1925): Plato. Complete works, vol. VIII: Statesman, Philebus, Ion, Cambridge: Loeb Classical Library.

ÉNDOXA: Series Filosóficas, n. ${ }^{\circ}$ 29, 2011, pp. 73-92. UNED, Madrid 
un conocimiento sistemático, y que la pretensión común de artistas de éxito a ser siervos útiles del público es probablemente una ilusión peligrosa». Ante esta situación, bien podría afirmarse del Ion aquello afirmado por Greene ${ }^{31}$ a propósito del punto de vista platónico de la poesía: «Cuando uno recuerda cuán divergentes son los puntos de vista de los más eminentes especialistas sobre esta cuestión, parece pertinente preguntar cómo son posibles tales diferencias de opinión en relación al mismo autor» (3). En mi opinión, si desde el punto de vista de su temática el Ion no ofrece duda sobre su condición platónica, en lo que respecta a su diseño formal, comparto la opinión de Moore ${ }^{32}$ de que se trata de una «obra maestra» (46). En el Ion el diseño y los contenidos están íntimamente entramados y eficazmente dirigidos a la consecución de un objetivo: sustraer la poesía tradicional y sus manifestaciones públicas del ámbito del conocimiento a fin de desacreditarla como modelo educativo del ciudadano griego. Paralelamente, frente al viejo modelo de discurso representado por la poesía tradicional, el diálogo propone un nuevo modelo, que es el representado por la dialéctica socrática. En este sentido, considero que no hay mucho que añadir a lo que ya afirmara Verdenius $^{33}$ en su conclusión final sobre el sentido del Ion: «No es sólo desde el punto de vista teórico que Sócrates considera importante explicar la diferencia entre el conocimiento irracional y el racional, sino que cree también que es su deber moral informar del peligro de tal conocimiento irracional. Así, negando la competencia de los rapsodas, los priva al mismo tiempo de sus pretensiones pedagógicas y de su derecho a guiar al pueblo» (262).

¿Cómo diseña Platón el diálogo a fin de conseguir el objetivo señalado? Tras la breve y cordial introducción del principio, Sócrates, en su primera intervención, establece el par de opuestos en torno al cual va a girar todo el diálogo posterior, cuando, al referirse al rapsoda, señala como función del mismo «llegar a conocer su pensamiento, y no sólo sus palabras» (tền toútou [poiętoû] dianoian ekmantbánein, mè mónon tà épe $),(. .$.$) , "pues no sería un buen rapsoda si no entendiera lo$ dicho por el poeta» (ou gàr àn génoitó pote agathòs rapsoidós, ei mè syneie ta legòmena bypo tô̂ poietoûu (530b-c). De este modo, Sócrates sitúa eficazmente el diálogo en la

${ }^{31}$ Greene, W. Ch. (1918): «Plato's View of Poetry», Harvard Studies in Classical Philology, vol 29 , pp. $1-75$.

32 Moore, J. D. (1973): «Limitation and Design in Plato’s Ion», Pacific Coast Philology, Vol. 8, pp. $45-51$.

${ }^{33}$ Verdenius, W. J. (1943): «L' Ion de Platon», Mnemosyne III, 11, pp. 233-62. 
oposición las palabras / el entendimiento (=las cosas dichas), tà épe / he dianoia (=ta legòmena), como ilustración de lo que va a constituir la oposición entre poesía y filosofía. A partir de aquí, el diálogo despliega un complejo juego de opuestos que remiten a aquella oposición inicial: aparecen los pares de opuestos dioses / verdad, téchne / enthousiasmós, pasividad / actividad, irracionalidad / racionalidad..., que nutren de contenido la oposición fundamental no conocimiento / conocimiento y, en última instancia, la oposición poesía / filosofía ${ }^{34}$. Así, cuando Sócrates se ofrece para hacer una exposición de lo que entiende por conocimiento, Ion le atribuye la condición de sabio: «Sí, por Zeus, lo deseo; pues me complazco escuchándoos a vosotros los sabios» (Naì mà tòn Día, ô Sókerates, égoge: chaíro gàr akoúon hymônn tôn sophôn $)$, condición que Sócrates rechaza tajantemente: «Desearía que fuera cierto lo que afirmas, oh Ion, pero quizás sabios sois vosotros, los rapsodas e intérpretes y aquellos cuyos poemas cantáis. Yo no digo otra cosa que la verdad, como corresponde al hombre corriente» (Bouloimen án se alêthê légein, ô Ion: allà sophoi mén poú este bymeîs hoi rapsodoi kai hypokritai kai hôn hymeîs áidete tà poiémata, egò dè ondèn allo è talethê légo, hoîn eikos idióten ánthropon) (532d-e). Mientras que Ion y Homero aparecen caracterizados como sabios, Sócrates aparece ocupado en la verdad. Tal como ha señalado certeramente Trabattoni ${ }^{35}$, Platón está afirmando que la sabiduría (sophía) que le es reconocida al poeta nada tiene que ver con el significado gnoseológico de la ciencia (epistéme $)$ del filósofo o del technites. Por otro lado, la sabiduría del poeta está asociada al pasivo encuentro con la inspiración, mientras que el verdadero conocimiento está asociado a una consciente y activa búsqueda y adquisición. La oposición la establece tempranamente Sócrates cuando, ante el desinterés del rapsoda por otro poeta que no sea Homero, se dirige a él en los siguientes términos: «(...) para todos es patente que tú no estás capacitado para hablar acerca de Homero por técnica o por conocimiento» (pantì dêlon bóti téchne kai epistémei peri Homérou légein adýnatos ể) (532c), y posteriormente atribuir su capacidad rapsódica a la inspiración divina (enthusiasmós). De hecho, todo el diálogo gira manifiestamente en torno a esta oposición: las partes primera (531a-533d ) y tercera (536d-542b) del diálogo se centran en negar el carácter epistémico o técnico de la sabiduría poética, mientras que la parte central (533d536d) se ocupa de la descripción de la inspiración divina (enthusiasmós). Al negarle Sócrates a Ion el carácter de technitess, es decir, la condición de poseedor de una

\footnotetext{
${ }^{34}$ Un excelente diagrama del juego de vínculos y oposiciones desplegado por Platón en el Ion nos lo ofrece PADILLA, M. (1992):»Rhapsodic Plato? ION`s Re-representation», Lexis 9-10, p. 123.

35 Trabattoni, F. (1986): «Sul significato dello Ione platonico», Sandalio 8-9, p. 44.
} 
téchne que le suministre el control sobre un determinado ámbito de objetos, y atribuirle en cambio un enthusiasmós de origen divino, Sócrates está situando la actividad poética en el ámbito de la irracionalidad. A lo largo de todo el diálogo Platón vuelve una y otra vez sobre esta identificación, valiéndose para ello de la comparación de la actividad del rapsoda con la posesión de los coribantes (534a, 536c) y de las bacantes (534a), y del uso frecuente de un vocabulario que apunta al carácter pasivo e irracional de su actividad (katechómenos, éntheos, ékphron, enthousiazónton y sus derivados $)^{36}$. En resumen, lo que distingue la actividad poética (Ion, Homero) de la actividad filosófica (Sócrates, Platón) es que la segunda constituye un conocimiento, y la primera no. Pero hay más, pues lo que está en el centro del debate no es sólo una cuestión relativa al conocimiento, sino también un problema de naturaleza política y ética. Este problema es soberbiamente expuesto en la parte central del diálogo mediante la metáfora de la piedra magnética y los anillos imantados. La elección de la metáfora es acertada; en primer lugar, porque el término griego daktýlios (anillo) coincide casi totalmente con dáktylos (dactílico), el verso empleado por Homero en sus poemas. En segundo lugar, y más fundamental, porque el vínculo al que alude la imagen de los anillos imantados corresponde a un tipo de unidad precaria, precisamente el tipo de unidad que Platón atribuye a la sociedad educada en la poesía homérica. Se trata de una unidad litúrgica, homogeneizada, irracional y alienada. Es decir: una unidad que sólo acontece en el momento del espectáculo, desapareciendo una vez que el mismo ha finalizado; una unidad que no toma en consideración las diferencias entre los individuos y entre las clases sociales; una unidad basada en la conexión establecida por las emociones, objeto de la parte más baja del alma; una unidad, en fin, que no deriva del hombre consciente y autónomo, sino del hombre fuera de sí poseído por una fuerza externa y falto de una identidad estable, cuya imagen es la de Proteo (541e) ${ }^{37}$. Frente a la frágil unidad de la sociedad basada en las multitudinarias manifestaciones públicas de la poesía — «veinte mil personas» (535d) — , Platón reivindicará la unidad real y duradera proporcionada por la filosofía y su reducido grupo de elegidos. Platón reivindicará el papel

\footnotetext{
${ }^{36}$ Un útil apéndice del vocabulario del Ion y de su frecuencia de uso se encuentra en el valiosísimo libro de Bremer, J. (2005): Plato's Ion. Philosopby as performance, North Richland Hills: Bibal Press, pp. 379-92.

${ }^{37}$ Sobre todos estos aspectos de la poesía y la rapsodia, pueden consultarse los trabajos de Woolf, R. (1997): «The Self in Plato's Ion», Apeiron, 30, 3, pp. 189-210 y de ArANA, J. R. (1998): «El Ión, fundador de la hermenéutica occidental», Veleia, 15, pp. 257-76.
} 
de la filosofía en la ordenación del Estado y en la responsabilidad educativa del ciudadano. En este sentido, el diálogo Ion, lejos de ser una obra menor, constituye una pieza clave en el proceso de elaboración de dicho proyecto.

\section{Conclusión}

Hemos visto que los despectivos comentarios realizados por los carismáticos Goethe y Schleiermacher sobre el Ion platónico provocaron serias dudas entre los platonistas alemanes del siglo XIX acerca de la autoría platónica del diálogo. De hecho, grandes autores del momento como Ast, Zeller y Wilamowitz rechazaron explícitamente la autoría platónica del breve diálogo. A este rechazo se unió, salvo contadas excepciones, una escasa valoración literaria y filosófica del mismo, ya no sólo durante el siglo XIX y en el ámbito académico alemán, sino también durante gran parte del siglo XX y en el ámbito anglosajón. Sin embargo, en lo relativo a su autoría, hemos visto que no hay ninguna razón seria para pensar que no se trate de una obra genuina de Platón; en efecto, tanto el estilo literario del diálogo como sus contenidos filosóficos son indudablemente platónicos, amén de otras circunstancias relativas a la transmisión de la obra de Platón, como es el hecho de que ninguno de los diálogos considerados espurios en la antigüedad aparezca en las tetralogías recogidas por Diógenes de Laercio. Finalmente, en lo relativo al valor literario y filosófico del diálogo, cabe concluir que el Ion no solamente constituye una obra maestra de diseño literario, sino también un paso fundamental en el proyecto platónico de suplantar el papel de la poesía en el monopolio educativo de la polis en favor del discurso filosófico representado por Sócrates y por el propio Platón.

\section{BIBLIOGRAFÍA}

ARANA, J. R. (1998). «El Ión, fundador de la hermenéutica occidental», Veleia, 15, pp. 257-76.

Asт, F. (1818). Platons Leben und Schriften, Leipzig.

Bekker, I. (1816). Platonis Dialogui, Graece et Latine, Berolini: Imprisis GE. Reimini.

Bredlow, L.-A. (ed.) (2010): Diógenes Laercio. Vidas y opiniones de los filósofos ilustres. Zamora: Lucina. 
Bremer, J. (2005). Plato's Ion. Philosophy as performance, North Richland Hills: Bibal Press.

Campbell, P. N. (1986). «The Ion: Argument and Drama», Res Publica litterarum 9, 59-68.

Diller, H. (1955). «Probleme des Platonischen Ion», Hermes, 83, pp. 171-187.

DiLthey, W. (1970). Leben Schleiermachers, Berlin [1898].

Dobson, W. (ed.) (1836). Schleiermacher. Introductions to the Dialogues of Plato. CambridgeLondon.

Dümmler, F. (1882). Antisthenica, Halle.

Ficino, M. (1993). Sobre el furor divino y otros textos, selección de textos, introducción y notas de Pedro Azara, traducción de Juan Maluquer y Jaime Sainz, Barcelona: Anthropos.

Flashar, H. (1958). Der Dialog Ion als Zeugnis platonischer Philosophie, Berlin: Akademie Varlag.

Gadamer, H.-J. (1969). «Schleiermacher platonicien», Archives de Philosophie, 28-39.

Goethe (1797): Plato als Mittgenosse einer Christlichen Offenbahrung, en GRUMACH, E. (1949): Goethe und die Antike, Berlín: De Gruyter, II, 758-762.

Greene, W. Ch. (1918). «Plato’s View of Poetry», Harvard Studies in Classical Philology, vol 29, pp. 1-75.

Grote, G. (1867). Plato and the Other Companions of Socrates, London.

Grumach, E. (1949). Goethe und die Antike, Berlín: De Gruyter.

Guthrie, W. K. C. (1990). Historia de la Filosofía Griega. IV: Platón. Platón. El hombre y sus diálogos: primera época, Madrid: Gredos [1062].

Hermann, K. F. (1976). Geschichte und System der Platonischen Philosophie, New York: Arno [1839].

Janell; W. (1901). Quaestiones Platonicae, Neue Jahrbicher fiir Philologie, Supp. 26.

JowetT, B. (1914). The dialogues of Plato, 4 vol., New York, [1871].

KRÄMER, H. J. (1989). Platone e i fundamenti della metafisica. Saggio sulla teoria dei principi e sulle dottrine non scritte di Platone, Milano: Vita e Pensiero.

Lamb, W. R. M. (1925). Plato. Complete works, vol. VIII: Statesman, Pbilebus, Ion, Cambridge: Loeb Classical Library.

Meridier, E. (1978). Platon. Oeuvres Complètes, Paris: Les belles lettres [1931].

Meyer, E. (1899). Forschungen zur alten Geschichte, Halle. 
Moore, J. D. (1973). «Limitation and Design in Plato’s Ion», Pacific Coast Philology, Vol. 8, pp. 45-51.

Moreau, J. (1939). «Les thèmes platoniciens de l' Ion de Platon», Revue des études grecques, 52, pp. 419-428.

Nitzsch, G. G. (1822). Platonis dialogus Ion, Lipsiae.

Отт, S. D. (1992). A commentary on Plato's Ion, Dissertation for the degree of PhD., Ann Arbor (MI): UMI.

Padilla, M. (1992). «Rhapsodic Plato? ION`s Re-representation», Lexis 9-10, p. 121143.

Philip, J. A. (1970). «The Platonic Corpus», Phoenix, Vol. 24, no 70, 296-308.

Pradeau, J.-F. (2001). Platon. Ion, suivi de Édouard Mehl: Deux lectures de l'Ion: M. Ficin et J. W. Goethe et Jean-Luc Nancy: Le partage des voix. Paris: Ellipses.

Reale, G. (2003). Por una nueva interpretación de Platón. Relectura de la Metafísica de los grandes diálogos a la luz de las doctrinas no escritas, Barcelona: Herder [1993].

Rujksbaron, A. (Ed.) (2007). Plato. Ion. Or: On the Iliad. Edited with Introduction and Commentary, Leiden-Boston: Brill.

RITTER, C. (1888). Untersuchungen über Plato, Stuttgard.

Schleiermacher, D. (2010). Platons Werke, Charleston: Nabu Press [1804-1828].

STÄHLIN, F. (1901). Die Stellung der Poesie in der platonischen Philosophie, Munich.

Stallbaum, G. (1857). Prolegomena ad Ionem, Gothae et Erfordiae: Sumptibus Hennings.

TAylor, A. E. (1926). Plato: the Man and his Work, London.

Tigerstedt, E. N. (1969). «Plato's Idea of Poetical Inspiration», Commentationes Humanarum Litterarum, 44, Helsinki: Societas Scientiarum Fennica.

Trabattoni, F. (1986). «Sul significato dello Ione platonico», Sandalio 8-9, p. 44. p. $27-$ 57.

Verdenius, W. J. (1943). «L' Ion de Platon», Mnemosyne III, 11, pp. 233-62.

v. Wilamowitz-Mollendorf, U. (1893). Aristoteles und Athen, Berlin: Weidmann.

- (1920). Platon, 2 vol., Berlin.

Woolf, R. (1997). «The Self in Plato’s Ion», Apeiron, 30, 3, pp. 189-210.

Zeller, E. (1875). Die Philosophie der Griechen, Leipzig.

Recibido: 6/11/2011

Aceptado: 10/04/2012 